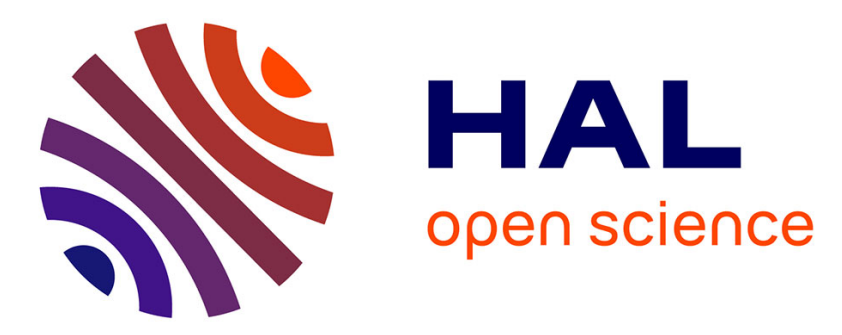

\title{
Polymer encapsulation and stabilization of molecular gel-based chiroptical information for strong, tunable circularly polarized luminescence film
}

Hisashi Oishi, Sayaka Mashima, Yutaka Kuwahara, Makoto Takafuji, Kyohei Yoshida, Reiko Oda, Hongdeng Qiu, Hirotaka Ihara

\section{To cite this version:}

Hisashi Oishi, Sayaka Mashima, Yutaka Kuwahara, Makoto Takafuji, Kyohei Yoshida, et al.. Polymer encapsulation and stabilization of molecular gel-based chiroptical information for strong, tunable circularly polarized luminescence film. Journal of Materials Chemistry C, 2020, 8, pp.8732 - 8735 . 10.1039/d0tc01480j . hal-03081845

\section{HAL Id: hal-03081845 https://hal.science/hal-03081845}

Submitted on 21 Dec 2020

HAL is a multi-disciplinary open access archive for the deposit and dissemination of scientific research documents, whether they are published or not. The documents may come from teaching and research institutions in France or abroad, or from public or private research centers.
L'archive ouverte pluridisciplinaire HAL, est destinée au dépôt et à la diffusion de documents scientifiques de niveau recherche, publiés ou non, émanant des établissements d'enseignement et de recherche français ou étrangers, des laboratoires publics ou privés. 



\title{
Polymer encapsulation and stabilization of molecular gel-based chiroptical information for strong, tunable circularly polarized luminescence film $†$
}

\author{
Hisashi Oishi, ${ }^{a}$ Sayaka Mashima, ${ }^{a}$ Yutaka Kuwahara, (D) ${ }^{a}$ Makoto Takafuji, (D) ${ }^{a}$

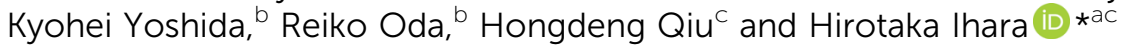

\begin{abstract}
We demonstrate a strategic approach for a completely organic, chiroptical polymer film, exhibiting strong $\left(g_{\text {lum }}=0.01-0.05\right)$ and broad-band circularly polarized luminescence that can be realized by the stabilization of self-assembly-driven secondary chirality through polymer encapsulation.
\end{abstract}

Circularly polarized luminescence (CPL) has attracted attention as a next-generation light signal because it carries more information due to its chirality and no angular effect compared to normal and linearly polarized lights. A simple example can be seen in its use as a communication tool by some animals. ${ }^{1}$ One technical approach for producing CPL is by converting polarized light from normal to linear using a quarter-wave plate. However, this approach can suffer from serious reductions in light energy with removal of light. The other solution for CPL generation is the use of chiral luminescent compounds that are totally organic. ${ }^{2-8}$ Studies using this approach have realized stronger CPL by precise molecular design, skilled organic synthesis, and careful purification. Therefore, gram-scale synthesis has not yet been achieved without few exceptions. ${ }^{8,9}$ In this work, we describe the fabrication of chiroptical polymer films that exhibit strong CPL and anticipate their possible applications in bio-sensing, chiroptical memory, detector system for security devices, and storage units. ${ }^{4,11}$ For such purposes, gram-scale synthesis becomes increasingly more important.

We selected a binary system for CPL generation, ${ }^{6,7}$ which has a distinct advantage on larger scale. Instead of using

\footnotetext{
${ }^{a}$ Department of Applied Chemistry and Biochemistry, Kumamoto University, 2-39-1 Kurokami, Chuo-ku Kumamoto 860-8555, Japan. E-mail: ihara@kumamoto-u.ac.jp

${ }^{b}$ Institut de Chimie \& Biologie des Membranes \& des Nano-objects (UMR5248 CBMN), CNRS, Université de Bordeaux, 2 rue Robert Escarpit, 33607 Pessac, France ${ }^{c}$ Institute of Chemical Physics, Chinese Academy of Science, Lanzhou 730000 , P. R. China

$\dagger$ Electronic supplementary information (ESI) available: Experimental and characterization details; confocal microscopy images and CD spectra of other systems. See DOI: $10.1039 /$ dotc01480j
}

specially designed chiral luminescent materials, commercially available, non-chiral luminescent dyes can be used and chirality can be induced by chiral templates. Therefore, the essential problem becomes, rather than the scalability of synthesis and fabrication, the retention of chirality induction in the polymer system. In this study, we demonstrate that strong CPL-exhibiting polymer films can be fabricated by incorporating into the polymer a chirally self-assembled CPL-inducing system consisting of a nonchiral luminescent dye and associated chiral template.

We applied several cyanine dyes including anionic NK-2012 and cationic NK-77 as non-chiral luminescent species for CPL generation. Because these cyanine dyes are very sensitive to the chiral microenvironment, they function as good indicators for chirality evaluation. However, cyanine dyes are often unstable, especially in oxygen atmosphere under sunlight, and therefore, these systems are not suitable for our present purpose. Fig. 1 presents several commercially available fluorescent dyes as new chirality-induction candidates. To induce chirality in these non-chiral dyes, $\boldsymbol{G}$-ca, having a carboxy head group, was chosen as a self-assembling organogelator (Fig. 1). The advantages of $\boldsymbol{G}$-ca can be summarized in terms of (1) its good solubility in various organic solvents, which is very important because most of a bulk polymer system is hydrophobic and used in organic media; (2) the enhanced chirality due to the formation of

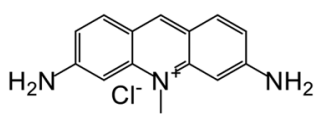

AC

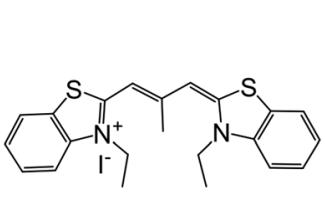

NK-77
BR-5

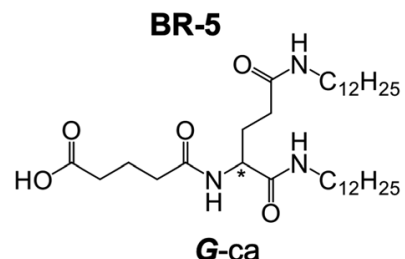<smiles>Cc1cc2c(cc1N)=[N+]c1cc(N(C)C)ccc1N=2</smiles>

Fig. 1 Chemical structures of non-chiral fluorescent compounds and organogelator $\mathbf{G}$-ca used in this study. 
secondary chirality through chiral arrangement; (3) its ionizability to promote electrostatic interactions with the cationic dyes shown in Fig. 1; and (4) its possible gram-scale synthesis via a one-step coupling reaction between L-glutamide ${ }^{12}$ and glutalic anhydride.

Mixed systems of $\boldsymbol{G}$-ca and dyes were prepared by the following procedure: a $0.5 \mathrm{mM}$ solution of $\boldsymbol{G}$-ca in toluene was prepared by heating at $85{ }^{\circ} \mathrm{C}$; cooling to $25{ }^{\circ} \mathrm{C}$ produced a clear solution. If the concentration was higher than a few millimolar in toluene, the solution became a clear gel. This phenomenon has been recognized as molecular gelation. ${ }^{7,13,14}$ Fig. 2a shows the TEM image of the $0.5 \mathrm{mM} \boldsymbol{G}$-ca solution after staining with uranyl acetate. $\boldsymbol{G}$-ca forms nano-fibrillar aggregates whose smallest diameter is within $50 \mathrm{~nm}$ in the photo. This indicates that the gelation behavior is the result of entanglement among the well-developed nano-fibrillar aggregates of $\boldsymbol{G}$-ca. Next, a methanolic solution of the dye was mixed in a given molar ratio with the $\boldsymbol{G}$-ca solution. No significant change is observed by TEM, but confocal microscopy provides fibrillar fluorescence images, as shown in Fig. 2b. Since $\boldsymbol{G}$-ca does not itself fluoresce, the obtained confocal image indicates that the dye is combined with $\boldsymbol{G}$-ca and the fibrillar aggregation of $\boldsymbol{G}$-ca is maintained after mixing with the dye.

The chirality of the $\boldsymbol{G}$-ca/dye mixed systems was investigated by CD spectroscopy. As shown in Fig. 3a, the $\boldsymbol{G}$-ca/NK-77 system exhibits a new exciton coupling $\left([\theta]_{573}=5 \times 10^{4} \mathrm{deg} \mathrm{cm} \mathrm{dmol}^{-1}\right)$ near the absorption band $\left(\lambda_{\max }=570 \mathrm{~nm}\right)$ of NK-77. Since NK-77 is non-chiral, the observed CD can be attributed to induced chirality from the $\boldsymbol{G}$-ca aggregates. Although this induced CD intensity is not so small, while we have confirmed much larger values $(>1 \times$ $\left.10^{6} \mathrm{deg} \mathrm{cm} \mathrm{dmol}^{-1}\right)^{15}$ in the case of an anionic cyanine dye, NK-2012, on poly(L-lysine). Therefore, we examined the effect of additives on the $\boldsymbol{G}$-ca/dye system to promote their interaction.
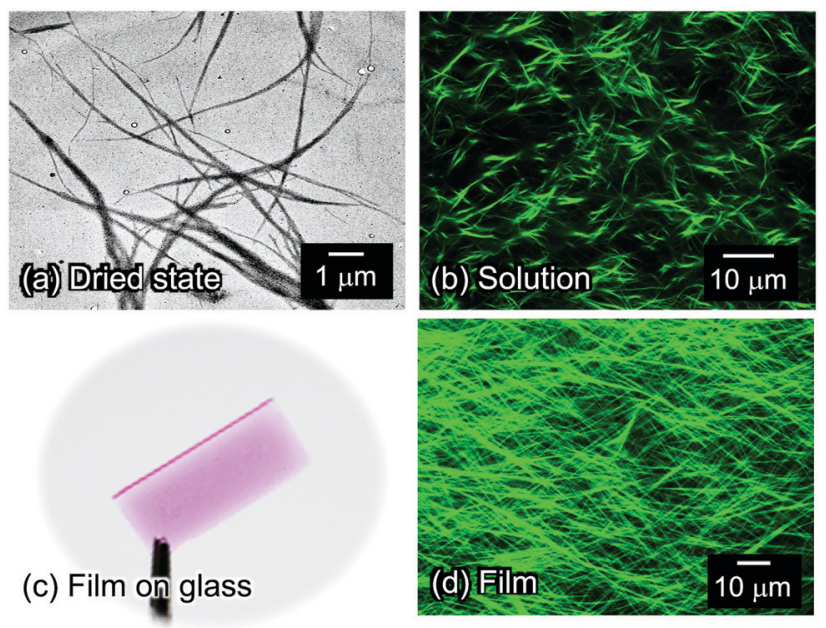

Fig. 2 TEM and confocal micrographs of $\mathbf{G}$-ca aggregates. (a) Initial concentration of $\mathbf{G}$-ca: $0.1 \mathrm{mM}$ in toluene. The dried sample was obtained by drop-casting on Cu mesh, stained with uranyl acetate and dried at room temperature. The confocal microscopy for the solution state (b) and the film (d) were observed with excitation wavelength at $488 \mathrm{~nm}$. (b) G-ca: $0.5 \mathrm{mM}$ and NK-77: $0.01 \mathrm{mM}$ in toluene. (c) and (d) G-ca: 2 wt\% in polystyrene. G-ca: NK-77= $20: 1$.

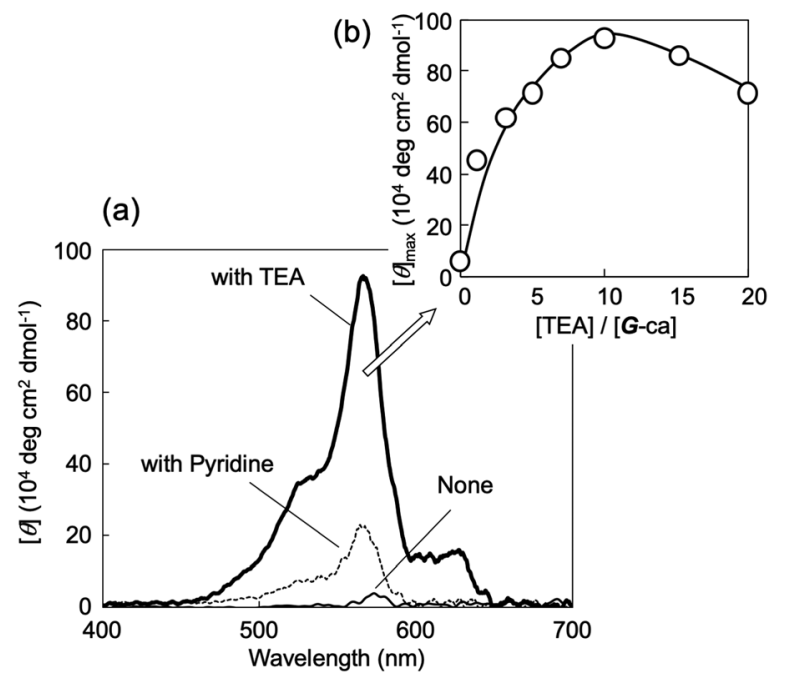

Fig. 3 (a) CD spectra of the $\mathbf{G}$-ca with NK-77 in toluene. [G-ca] $=0.5 \mathrm{mM}$; [NK-77] $=0.01 \mathrm{mM}$; [TEA] or [pyridine] $=5 \mathrm{mM}$. (b) Effect of TEA additive in the $\mathbf{G}$-ca/dye system on the CD intensity.

When an organic amine such as pyridine or triethylamine (TEA) is added to the $\boldsymbol{G}$-ca/dye system, a distinct increase in CD intensity is observed. Fig. 3b shows the effect of TEA on the CD spectrum. The peak intensity is amplified ca.20 times with the addition of ten equimolar of $\boldsymbol{G}$-ca. This is probably due to the promotion of electrostatic interactions between the chiral $\boldsymbol{G}$-ca and non-chiral NK-77 by neutralization of the iodide counter ion of NK-77. Therefore, in this study, TEA was applied in the promotion of induced CD for the other non-chiral dyes.

Polystyrene (PS) was selected as the bulk polymer for film fabrication. The typical fabrication procedure is as follows: a $5 \mathrm{wt} \%$ solution of PS was combined with $\boldsymbol{G}$-ca in hot toluene, and then the methanolic dye solution was added to the mixture. Part of the mixture $(400 \mu \mathrm{L})$ was drop-cast onto a glass plate $(12 \mathrm{~mm} \times 25 \mathrm{~mm})$ and dried in air. The thickness of the resultant polymer film was adjusted to be approximately $60 \mu \mathrm{m}$. The main composition rate was adjusted to be $2.0 \mathrm{wt} \%$ in the $\boldsymbol{G}$-ca-in-polymer, and to be 1:20 in the molar ratio of dye and $\boldsymbol{G}$-ca. Fig. 2d shows the confocal microscopy images of the PS film containing NK-77 with $\boldsymbol{G}$-ca. The fibrillar fluorescence image indicates that not only does $\boldsymbol{G}$-ca self-assemble in the polymer, but also that NK-77 is associated with the $\boldsymbol{G}$-ca fibrils. Similar fluorescence images (Fig. S1, ESI $\dagger$ ) were observed with the other dyes, including acriflavine $\left(\mathrm{AC}, \lambda_{\max }=530 \mathrm{~nm}\right)$ and Basic Red-5 (BR-5, $\left.\lambda_{\max }=591 \mathrm{~nm}\right)$. Notably, all the PS films are transparent, which means that the diameters of the aggregates are sufficiently small to escape the problem of undesirable light scattering. This is an essential and important requirement for optical applications, and therefore, we conclude that our strategic approach is unquestionably suitable for our research purposes.

Fig. 4 shows the CD spectra of the PS films containing the $\boldsymbol{G}$-ca/dye systems. Large CD intensities are observed near the absorption bands of the dyes in all films. Since no CDs are observed in the absence of $\boldsymbol{G}$-ca and the CD intensity is 
(a) NK-77

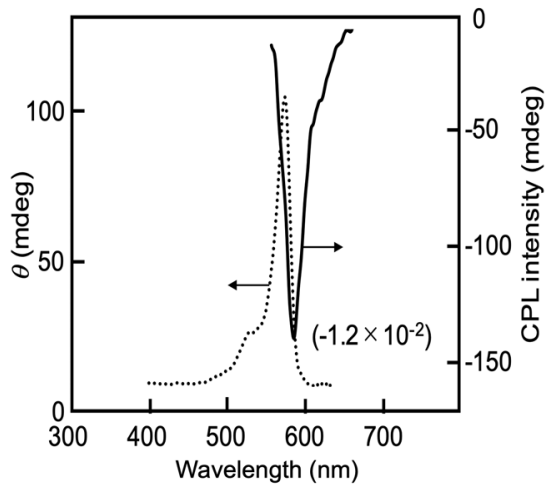

(b) AC

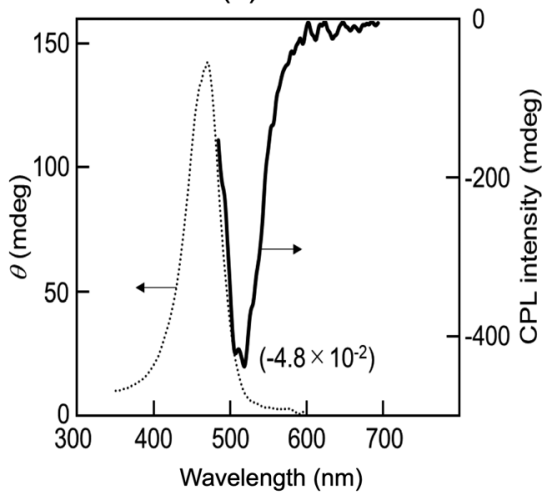

(c) BR-5

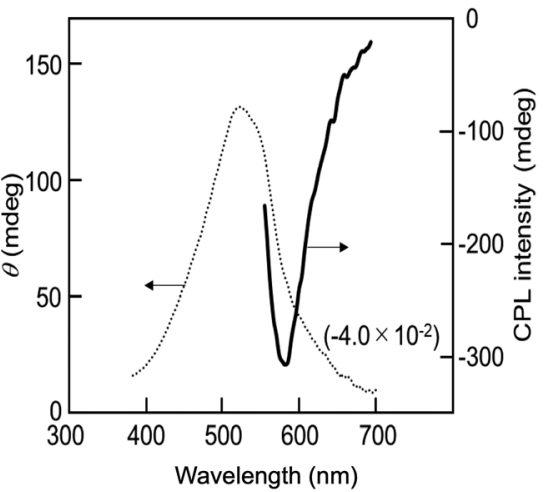

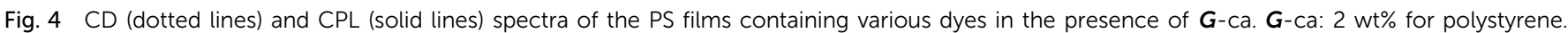

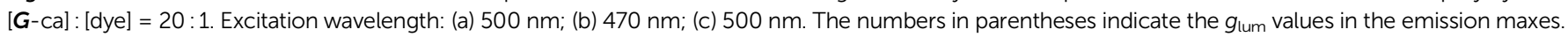

distinctly decreased without TEA, it is clear that the dyes are chirally perturbed by the $\boldsymbol{G}$-ca chiral aggregates. Fig. 4 also includes the CPL spectra. The emission bands agree with the fluorescence bands of the dyes (Fig. S2, ESI $\dagger$ ), and the values of $g_{\text {lum }}$ reach $-0.012,-0.048$ and -0.040 with NK-77, AC and BR-5, respectively. A $\left|g_{\text {lum }}\right|$ value over 0.04 corresponds to the highest value in the polymer thin film system.

Our CPL generation system has multiple advantages. First, mixed-dye systems can be employed to provide broad-band CPL over a wide range of emission bands. For example, when AC and BR-5 are mixed, the resultant PS film provides two CD signals (Fig. S3, ESI $\dagger$ ). Second, broad-band CPL can also be generated by adjusting the chiral microenvironment. For example, when the mixing ratio of AC to $\boldsymbol{G}$-ca is adjusted, the luminescent peak width increases as shown in Fig. 5: that is, the Stokes shift can be made tunable by promoting the heterogeneity of chiral perturbation. Finally, by encapsulating $\boldsymbol{G}$-ca in the polymer as well as selecting the proper dye, the CPL phenomenon can be remarkably stabilized. For example, we confirmed that the $\boldsymbol{G}$-ca/AC polymer system maintained strong CPL over at least a month.

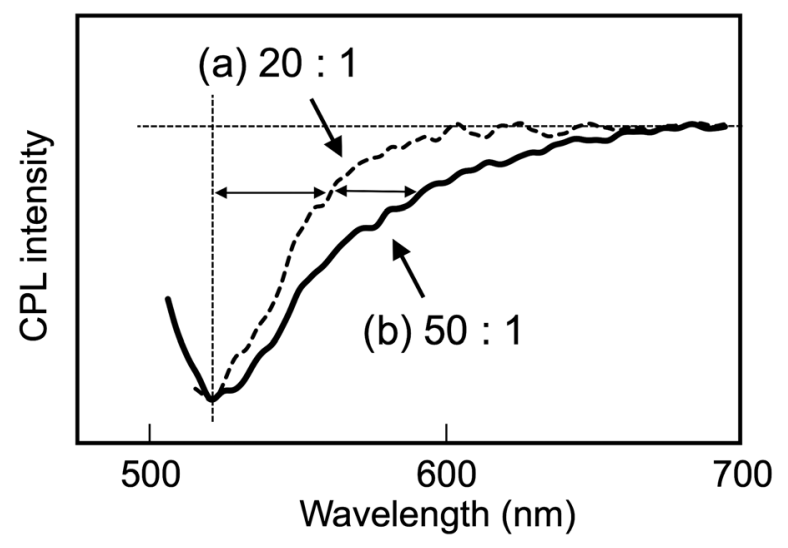

Fig. 5 Promotion of band broadening of the luminescence by adjusting the $\boldsymbol{G}$-ca concentration in the PS film. [G-ca] = (a) $0.2 \mathrm{mM}$; (b) $0.5 \mathrm{mM}$. Dye (AC): $0.01 \mathrm{mM}$. Emission wavelength: $500 \mathrm{~nm}$.

\section{Conclusions}

In conclusion, we have established a strong CPL $\left(g_{\text {lum }} \approx 0.05\right)$ generation system in a polymer thin film. Our system is advantageous because no chirality is needed in the fluorescent component, meaning that it is free from precise molecular design and complicated synthetic limitations, and therefore possible for industrial-scale application. In addition, the emission bands can be readily tuned by adjusting the molecular orientation of the chiral template system as well as the dye selection. These advantages could expand possible system applications, such as in optical uses (e.g., chiroptical detector for bio-signal sensing), in agriculture, or in solar cells as a reduced-angular wavelength converter.

\section{Conflicts of interest}

There are no conflicts to declare.

\section{Acknowledgements}

This work was supported by the French-Japanese International Associated Laboratory, Chiral Nanostructures for Photonic Applications (LIA-CNPA), and a Japan Society for the Promotion of Science Grant-in-Aid for Scientific Research and the Bilateral Joint Research project.

\section{Notes and references}

1 (a) G. C. McLeod, Luminol. Oceanogr., 1957, 2, 360; (b) H. Wynberg, E. W. Meijer, J. C. Hummelen, H. P. J. M. Dekkers, P. H. Schippers and A. D. Carlson, Nature, 1980, 286, 641; (c) T.-H. Chiou, S. Kleinlogel, T. Cronin, R. Caldwell, B. Loeffler, A. Siddiqi, A. Goldizen and J. Marshall, Curr. Biol., 2008, 18, 429; (d) P. P. Shibayev and R. G. Pergolizzi, Int. J. Bot., 2011, 7, 113.

2 (a) J. E. Field, G. Muller, J. P. Riehl and D. Venkataraman, J. Am. Chem. Soc., 2003, 125, 11808; (b) H. Maeda, Y. Bando, K. Shimomura, I. Yamada, M. Naito, K. Nobusawa, H. Tsumatori and T. Kawai, J. Am. Chem. Soc., 2011, 
133, 9266; (c) Y. Sawada, S. Furumi, A. Takai, M. Takeuchi, K. Noguchi and K. Tanaka, J. Am. Chem. Soc., 2012, 134, 4080; (d) E. M. Sánchez-Carnerero, F. Moreno, B. L. Maroto, A. R. Agarrabeitia, M. J. Ortiz, B. G. Vo, G. Muller and S. de la Moya, J. Am. Chem. Soc., 2014, 136, 3346; (e) Y. Morisaki, M. Gon, T. Sasamori, N. Tokitoh and Y. Chujo, J. Am. Chem. Soc., 2014, 136, 3350; $(f)$ K. Nakamura, S. Furumi, M. Takeuchi, T. Shibuya and K. Tanaka, J. Am. Chem. Soc., 2014, 136, 5555; $(g)$ M. Gon, Y. Morisaki and Y. Chujo, J. Mater. Chem. C, 2015, 3, 521; (h) R. Clarke, K. L. Ho, A. A. Alsimaree, O. J. Woodford, P. G. Waddell, J. Bogaerts, W. Herrebout, J. G. Knight, R. Pal, T. J. Penfold and M. J. Hall, ChemPhotoChem, 2017, 1, 513; (i) T. Hosokawa, Y. Takahashi, T. Matsushima, S. Watanabe, S. Kikkawa, I. Azumaya, A. Tsurusaki and K. Kamikawa, J. Am. Chem. Soc., 2017, 139, 18512; $(j)$ K. Dhbaibi, L. Favereau, M. Srebro-Hooper, M. Jean, N. Vanthuyne, F. Zinna, B. Jamoussi, L. Di Bari, J. Autschbach and J. Crassous, Chem. Sci., 2018, 9, 735; (k) K. Kikuchi, J. Nakamura, Y. Nagata, H. Tsuchida, T. T. Kakuta, T. Ogoshi and Y. Morisaki, Chem. - Asian J., 2019, 14, 1681; (l) P. Reine, A. G. Campaña, L. A. de Cienfuegos, V. Blanco, S. Abbate, A. J. Mota, G. Longhi, D. Miguel and J. M. Cuerva, Chem. Commun., 2019, 55, 10685; (m) L. Guy, M. Mosser, D. Pitrat, J.-C. Mulatier, M. Kukułka, M. SrebroHooper, E. Jeanneau, A. Bensalah-Ledoux, B. Baguenard and S. Guy, J. Org. Chem., 2019, 84, 10870; (n) K. Dhbaibi, L. Favereau, M. Srebro-Hooper, C. Quinton, B. Jamoussi, J. Autschbach, N. Vanthuyne, L. Arrico, T. Roisnel, C. Poriel, C. Cabanetos and J. Crassous, Chem. Sci., 2020, 11, 567; (o) Y. Saito, M. Satake, R. Mori, M. Okayasu, H. Masu, M. Tominaga, K. Katagiri, K. Yamaguchi, S. Kikkawa, H. Hikawa and I. Azumaya, Org. Biomol. Chem., 2020, 18, 230.

3 (a) H. Tsumatori, T. Nakashima and T. Kawai, Org. Lett., 2010, 12, 2362; (b) H. Langhals, A. Hofer, S. Bernhard, J. S. Siegel and P. Mayer, J. Org. Chem., 2011, 76, 990; (c) T. Harada, M. Kurihara, R. Kuroda and H. Moriyama, Chem. Lett., 2012, 41, 1442; (d) K. Nakabayashi, T. Amako, N. Tajima, M. Fujiki and Y. Imai, Chem. Commun., 2014, 50, 13228; (e) M. Inouye, K. Hayashi, Y. Yonenaga, T. Itou, K. Fujimoto, T.-a. Uchida, M. Iwamura and K. Nozaki, Angew. Chem., Int. Ed., 2014, 53, 14392; $(f)$ J. Kumar, H. Tsumatori, J. Yuasa, T. Kawai and T. Nakashima, Angew. Chem., Int. Ed., 2015, 54, 5943; (g) M. Deng, L. Zhang, Y. Jiang and M. Liu, Angew. Chem., Int. Ed., 2016, 55, 15062; (h) D. Yang, P. Duan, L. Zhang and M. Liu, Nat. Commun., 2016, 8, 15727; (i) F. Salerno, J. A. Berrocal, A. T. Haedler, F. Zinna, E. W. Meijer and L. D. Bari, J. Mater. Chem. C, 2017, 5, 3609; (j) M. Górecki, F. Zinna, T. Biver and L. D. Bari, J. Pharm. Biomed. Anal., 2017, 144, 6; (k) M. Nakamura, F. Ota, T. Takada, K. Akagi and K. Yamana, Chirality, 2018, 30, 602; (l) H. Tanaka, Y. Inoue and T. Mori, ChemPhotoChem, 2018, 2, 386;
( $m$ ) S. Lee, K. Y. Kim, S. H. Jung, J. H. Lee, M. Yamada, R. Sethy, T. Kawai and J. H. Jung, Angew. Chem., Int. Ed., 2019, 58, 18878.

4 H. Li, H. Li, W. Wang, Y. Tao, S. Wang, Q. Yang, Y. Jiang, C. Zheng, W. Huang and R. Chen, Angew. Chem., Int. Ed., 2020, 59, 4756.

5 (a) H. Jintoku, M.-T. Kao, A. Del Guerzo, Y. Yoshigashima, T. Masunaga, M. Takafuji and H. Ihara, J. Mater. Chem. C, 2015, 3, 5970; (b) Y. Okazaki, T. Goto, R. Sakaguchi, Y. Kuwahara, M. Takafuji, R. Oda and H. Ihara, Chem. Lett., 2016, 45, 448.

6 (a) T. Goto, Y. Okazaki, M. Ueki, Y. Kuwahara, M. Takafuji, R. Oda and H. Ihara, Angew. Chem., Int. Ed., 2017, 56, 2989; (b) T. Ikai, M. Okubo and Y. Wada, J. Am. Chem. Soc., 2020, 142, 3254; (c) S. Mashima, N. Ryu, Y. Kuwahara, M. Takafuji, H. Jintoku, R. Oda and H. Ihara, Chem. Lett., 2020, 49, 368.

7 (a) H. Ihara, M. Takafuji and Y. Kuwahara, Polym. J., 2016, 48, 843; (b) Y. Sang, J. Han, T. Zhao, P. Duan and M. Liu, Adv. Mater., 2019, 31, 1900110; (c) H. Ihara, M. Takafuji, Y. Kuwahara, Y. Okazaki, N. Ryu, T. Sagawa and R. Oda, in Molecular Technology, Volume 4: Synthesis Innovation, ed. H. Yamamoto and T. Kato, Wiley-VCH, Weinheim, 2019, ch. 11, pp. 297-338.

8 J. Bosson, G. M. Labrador, S. Pascal, F.-A. Miannay, O. Yushchenko, H. Li, L. Bouffier, N. Sojic, R. C. Tovar, G. Muller, D. Jacquemin, A. D. Laurent, B. L. Guennic, E. Vauthey and J. Lacour, Chem. - Eur. J., 2016, 22, 18394.

9 (a) D. Poggiali, A. Homberg, T. Lathion, C. Piguet and J. Lacour, ACS Catal., 2016, 6, 4877; (b) A. Homberg, E. Brun, F. Zinna, S. Pascal, M. Gorecki, L. Monnier, C. Besnard, G. Pescitelli, L. D. Bari and J. Lacour, Chem. Sci., 2018, 9, 7043; (c) F. Zinna, S. Voci, L. Arrico, E. Brun, A. Homberg, L. Bouffier, T. Funaioli, J. Lacour, N. Sojic and L. D. Bari, Angew. Chem., Int. Ed., 2019, 58, 6952.

10 F. Zinna and L. Di Bari, Chirality, 2015, 27, 1.

11 R. Carr, N. H. Evans and D. Parker, Chem. Soc. Rev., 2012, 41, 7673.

12 H. Ihara, M. Yoshitake, M. Takafuji, T. Yamada, T. Sagawa, C. Hirayama and H. Hachisako, Liq. Cryst., 1999, 26, 1021.

13 (a) H. Ihara, M. Takafuji and T. Sakurai, in Encyclopedia of Nanoscience and Nanotechnology, ed. H. S. Nalwa, American Scientific Publishers, California, 2004, vol. 9, pp. 473-495; (b) R. Oda, in Molecular Gels, ed. R. G. Weiss and P. Terech, Springer, Berlin, 2006, pp. 577-612.

14 (a) Y.-C. Lin and R. G. Weiss, Macromolecules, 1987, 20, 414; (b) T. Shimizu, M. Masuda and H. Minamikawa, Chem. Rev., 2005, 105, 1401; (c) P. Xue, Q. Xu, P. Gong, C. Qian, A. Ren, Y. Zhang and R. Lu, Chem. Commun., 2013, 49, 5838; (d) P. Xue, J. Sun, B. Yao, P. Gong, Z. Zhang, C. Qian, Y. Zhang and R. Lu, Chem. - Eur. J., 2015, 21, 4712.

15 M. Shibata, H. Ihara and C. Hirayama, Polymer, 1993, 34, 1106. 